\title{
Sistemas Apostilados de Ensino e a autonomia ilusória: reflexões à luz de José Contreras
}

\author{
Gabriel Santos Ortiz ${ }^{\mathrm{L}, \mathrm{II}}$ \\ Luciano Denardin ${ }^{\text {III,IV }}$ \\ Pedro Savi Neto ${ }^{\mathrm{V}, \mathrm{VI}}$
}

\footnotetext{
Pontifícia Universidade Católica do Rio Grande do Sul (PUCRS). Porto Alegre, Rio Grande do Sul, Brasil. E-mail:<gabriel.ortiz@edu. pucrs.br >; <https://orcid. org/0000-0003-1650-4126>.

II Mestre em Educação em Ciências e Matemática pela Pontifícia Universidade Católica do Rio Grande do Sul (PUCRS). Porto Alegre, Rio Grande do Sul, Brasil.

III Pontifícia Universidade Católica do Rio Grande do Sul (PUCRS). Porto Alegre, Rio Grande do Sul, Brasil. E-mail: <luciano.denardin@ pucrs.br $>$; <https://orcid. org/0000-0001-8839-2229>.

IV Doutor em Educação em Ciências e Matemática pela Pontifícia Universidade Católica do Rio Grande do Sul (PUCRS). Porto Alegre, Rio Grande do Sul, Brasil.

v Pontifícia Universidade Católica do Rio Grande do Sul (PUCRS). Porto Alegre, Rio Grande do Sul, Brasil. E-mail:<p.savi@hotmail. com>; <https://orcid. org/0000-0001-8781-5277>.

vi Doutor em Educação pela Pontifícia Universidade Católica do Rio Grande do Su (PUCRS). Porto Alegre, Rio Grande do Sul, Brasil.
}

\section{Resumo}

Este ensaio teórico tem como objetivo debater a autonomia docente dentro dos Sistemas Apostilados de Ensino (SAEs). Apresentam-se argumentos para afirmar que o professor, inserido em um contexto de sistema apostilado, tem o seu trabalho regulado tanto pela escola quanto pela empresa e é afastado dos aspectos intelectuais, reflexivos e críticos da profissão, aproximando-se do modelo de profissional técnico. Dessa forma, mais do que influenciar o fazer docente, os sistemas contribuem com a desvalorização do trabalho do professor e retiram o protagonismo de toda a comunidade escolar na construção do processo educacional. Ainda assim, percebendo na literatura que muitos professores defendem o uso dos SAEs, buscou-se em Contreras (2012) o conceito de autonomia ilusória para tentar compreender tal posicionamento. Destaca-se que o apoio dos professores ao sistema que lhes controla vai ao encontro do conceito de servidão voluntária de La Boétie. A principal conclusão deste trabalho é que os SAEs continuam crescendo com o apoio daqueles que estão sob seu controle.

Palavras-chave: autonomia docente; professor técnico; Sistemas Apostilados de Ensino. 


\section{Abstract \\ Hand-out teaching systems and illusory autonomy: reflections based on José Contreras' theory}

This theoretical essay discusses teaching autonomy regarding the use of hand-out teaching systems (Sistemas Apostilados de Ensino, acronymed SAEs in Portuguese). In favor of teachers, it is argued that these conditions subject their work to be under the supervision of both the institution and the company, which then shuns them from the intellectual, reflexive and critical aspects of the profession and brings them closer to the technical professional model. Thus, these systems do more than inform teaching practice, they add to the devaluation of teaching, robbing all of the school community of the protagonism in the development of the educational process. Still, since it is evident that many teachers in the field's literature advocate for the use of $S A E^{\prime} s$, this essay sought in Contreras (2012) the concept of illusory autonomy to try to explain such positions. It should be noted that the support of teacher to a system that controls them meets La Boétie's concept of voluntary servitude. Therefore, the main conclusion herein is that $S A E^{\prime}$ 's continue to grow with the support of those under their control.

Keywords: hand-out teaching systems; teacher as technician; teacher's autonomy.

\section{Resumen \\ Sistemas Estandarizados de Enseñanza y la autonomía ilusoria: reflexiones basadas en la teoría de José Contreras}

Este ensayo teórico tiene como objetivo discutir la autonomía docente dentro de los Sistemas Estandarizados de Enseñanza (SEE). Se presentan argumentos para afirmar que el docente, insertado en un contexto de sistema estandarizado, tiene su trabajo regulado tanto por la escuela como por la empresa y se aleja de los aspectos intelectuales, reflexivos y críticos de la profesión, acercándose al modelo de profesional técnico. Así, más que influir en la profesión docente, los sistemas contribuyen a la devaluación del trabajo del docente y eliminan el protagonismo de toda la comunidad escolar en la construcción del proceso educativo. Sin embargo, identificando que muchos maestros en literatura abogan por el uso de los SEE, se usó el concepto de autonomía ilusoria de Contreras (2012) para tratar de entender esta posición de los docentes. Cabe señalar que el apoyo de los docentes al sistema que los controla está en línea con el concepto de servidumbre voluntaria de La Boétie. La principal conclusión de este trabajo es que los SEE continúan creciendo con el apoyo de quienes están bajo su control.

Palabras clave: autonomía docente; profesor técnico; Sistemas Estandarizados de Enseñanza. 


\section{Considerações iniciais}

A educação escolar tem atraído cada vez mais a atenção de grandes corporações, que passaram a investir altas quantias para dominar o setor educacional (Amorim, 2012). Há algumas décadas, as escolas se expandiam apenas pela criação de novas franquias, enquanto, atualmente, notam-se novas estratégias que visam evitar os riscos e os custos de administrar novas escolas. Observam-se grupos educacionais ofertando ações na bolsa de valores, fusões entre empresas do ramo educacional (escolas, cursos, universidades, editoras etc.) e sistemas de ensino, limitando-se a vender pacotes de serviços e materiais para escolas parceiras e para o Estado (Galzerano; Gobi; Luiz, 2011).

Nesse cenário, as escolas deixam de ser instituições comprometidas com a educação para se tornarem verdadeiras empresas regidas pela lógica do lucro, que precisam convencer seus clientes (estudantes e famílias) de que possuem um sistema de ensino atraente e eficiente (Laval, 2004). Para tanto, além da tradicional publicidade direcionada aos resultados em concursos vestibulares, já é possível observar escolas adotando campanhas de marketing focadas em determinadas "inovações" pedagógicas, como o ensino bilíngue, o ensino maker, as aulas de robótica, as aulas de empreendedorismo etc.

Cientes disso, redes educacionais, muitas delas oriundas de cursos preparatórios para o vestibular, passaram a desenvolver pacotes de serviços e materiais apostilados, vendendo a ideia de que seu método de ensino seria mais eficiente e traria melhores resultados para as escolas que o adotassem. Já sobrecarregados com todas as exigências e os desafios da rotina escolar, muitos gestores optam pela parceria com esses Sistemas Apostilados de Ensino (SAEs), acreditando que os materiais e a organização curricular do sistema trariam benefícios para a aprendizagem dos alunos e que a associação da escola com o sistema seria bem-vista por parte das famílias dos estudantes, ou seja, pelos seus clientes. Atualmente, estima-se que dezenas de milhares de escolas privadas brasileiras mantenham parcerias com algum SAE (Galzerano; Gobi; Luiz, 2011). Ademais, percebe-se que muitos municípios brasileiros, principalmente no estado de São Paulo, vêm realizando parcerias público-privadas nas últimas duas décadas com o objetivo de adotar SAEs das empresas privadas nas escolas da rede pública (Adrião et al., 2009).

Mesmo que os SAEs se configurem de maneiras distintas nas redes pública e privada, sua organização estruturada e altamente sistematizada tem um grande impacto no trabalho docente em ambos os cenários. Ao trazerem os conteúdos que devem ser trabalhados a cada bimestre com as apostilas, definirem toda a estrutura e sequência do currículo e oferecerem sugestões de condução das aulas e de atividades, tornam as práticas em sala de aula altamente controláveis. Ainda assim, pesquisas como as de Amorim (2012), Silva, E. A. (2013), Dantas; Almeida (2014), Damaso (2015), Silveira (2015), entre outras, mostram que, mesmo quando a adoção do sistema é realizada sem consulta ao corpo docente, uma parcela importante dele se 
mostra favorável a ela, visto a suposta facilidade que ele proporciona ao trabalho dos professores e a crença na melhora da qualidade do ensino. Além disso, quando questionados sobre a interferência dos sistemas na sua autonomia profissional, muitos professores afirmam que se sentem autônomos devido à suposta liberdade que têm para decidir a forma como serão ministradas suas aulas, quais tópicos deverão receber uma ênfase maior, a ordem que querem trabalhar os conteúdos do bimestre e se devem, ou não, realizar atividades de reforço não previstas.

Pensando sobre o exposto, o questionamento que orienta o debate proposto neste ensaio é: quais motivos levam os professores submetidos à estrutura de um SAE a defenderem um sistema que diminui sua autonomia e descaracteriza parte importante do processo de educar? Com o objetivo de oferecer argumentos à questão, este texto visa compreender e debater o posicionamento desses professores à luz das ideias sobre autonomia docente de Contreras (2012).

Na primeira seção, descrevem-se as características básicas dos SAEs e de seus materiais. A segunda seção apresenta, com base em Contreras (2012), os diferentes modelos de professor e seus respectivos conceitos de autonomia. Na terceira seção, são apresentadas as pesquisas empíricas encontradas na literatura que investigam as opiniões dos professores ao trabalharem com algum SAE. A quarta seção visa relacionar os pontos de vista dos professores participantes das pesquisas com o conceito de autonomia ilusória defendido por Contreras (2012). Por fim, os principais elementos e argumentos do texto são retomados nas considerações finais.

\section{Os Sistemas Apostilados de Ensino}

De acordo com Bego (2013), os SAEs têm sua primeira grande expansão na década de 1990, acompanhando o crescimento dos cursos preparatórios ("cursinhos"), principalmente aqueles com foco no vestibular. Como salienta o autor, os cursos preparatórios se tornaram especialistas no treinamento de estudantes para as provas, tendo como principal objetivo a aprovação nos vestibulares. Sendo essas provas altamente conteudistas e competitivas, desenvolveu-se, nesses ambientes, um ensino altamente expositivo, com professores buscando transmitir aos estudantes o máximo possível do conteúdo necessário para as provas e os procedimentos e as técnicas a serem utilizados na resolução dos diversos tipos de exercícios. Essa conduta privilegia a absorção passiva e a memorização de tudo que foi apresentado para posterior reprodução na prova, deixando de lado discussões de aspectos éticos e estéticos que não são exigidos nesses exames. Focados nesse objetivo, os cursinhos conseguiam (e ainda conseguem) altos índices de aprovação, construindo uma imagem de sistema de ensino de "qualidade".

Com o aumento do prestígio, esses sistemas privados de ensino e o mercado editorial passaram a atrair atenção e investimentos empresariais que viam nesse setor uma grande possibilidade de crescimento. Transformando-se de pequenos cursos para grandes empresas, muitos 
desses sistemas de ensino passaram a se expandir pelo País via sistema de franquias, criando fortes redes de cursos preparatórios para o vestibular e, atualmente, para o Exame Nacional do Ensino Médio (Enem). Não demorou muito para que esses sistemas se envolvessem com escolas privadas e induzissem o desenvolvimento de uma educação escolar apostilada, com foco na preparação para exames de seleção ao ensino superior. Além disso, ao adotar a franquia, as escolas também implementavam muitos outros instrumentos e práticas pedagógicas ofertadas pelos sistemas, como materiais digitais, portais educativos na internet, assessoria pedagógica, formação continuada dos professores e até mesmo a ideologia de ensino (Bego, 2013). Assim, até o início do século 21, o capital manteve sua ampliação no campo educacional, predominantemente no setor privado, incorporando concorrentes de menor porte e aumentando o número de franquias por meio da venda de seus sistemas de ensino.

Foi só no final da década de 1990 que o grande capital começou a se expandir rapidamente na educação pública. De acordo com Adrião et al. (2009), dois fatores parecem ter influenciado fortemente o processo: a estagnação da educação privada e a municipalização do ensino fundamental. Despreparados e sem estrutura adequada para gerir essa etapa educacional, muitos municípios, principalmente os de pequeno porte, enfrentaram diversas dificuldades para manter o ensino fundamental em bom funcionamento. Em meio a essas dificuldades, muitos prefeitos optaram pela realização de parcerias com empresas privadas, acreditando que isso aproximaria, em termos de qualidade, a educação pública da educação privada. Entre as diferentes formas de parcerias, diversos municípios, principalmente do interior paulista, têm adotado os sistemas de ensino de empresas privadas com o discurso de melhoria da qualidade da educação no município (Adrião et al., 2009).

Atualmente, essas empresas se converteram em grandes grupos empresariais, muitas delas proprietárias não só de SAEs, mas também de editoras, escolas, cursos e até universidades. De acordo com Adrião et al. (2016), no momento de sua pesquisa, os cinco maiores grupos empresariais atuando no campo educacional por meio da oferta de serviços e produtos educacionais para o setor público brasileiro eram: Grupo Objetivo, Grupo Positivo, Grupo Pearson, Grupo Santillana e SOMOS Educação.

Tendo compreendido a história desses sistemas, faz-se necessário definir com mais detalhes aquilo que será entendido por SAE. Uma das principais características que se verifica nesses sistemas, desde que começaram a ser comercializados, é o uso de apostilas ao invés dos livros didáticos. Para Pieroni (1998, p. 67), as apostilas são materiais em que:

[...] o conteúdo curricular das disciplinas encontra-se dividido e organizado em um número determinado de aulas que coincidem com a programação mensal prevista que impõe às unidades franqueadas o número necessário de aulas de cada disciplina em cada série para que a aplicação do material seja correta e não atrase. O esquema das aulas presentes nas apostilas contém uma parte teórica, geralmente textos básicos explicativos, espaço para anotações dos alunos, uma série de exercícios e um conjunto de tarefas mínimas e complementares. 
Por mais que as apostilas possam variar em diversos aspectos entre as empresas, pesquisas, como as de Amorim (2008) e Bego (2013), parecem indicar determinadas características sempre presentes, como: a menor profundidade nos conteúdos, o foco no treinamento de exercícios do vestibular e/ou Enem, as sugestões de sequências didáticas e de atividades de aula e a estruturação em pequenos módulos para serem finalizados em curtos períodos do ano letivo.

Ainda assim, esses sistemas não se limitam apenas à venda desses materiais, ofertando também diversos produtos e serviços que prometem qualificar o ensino na escola parceira. Nesse sentido, para Adrião et al. (2009, p. 806):

\begin{abstract}
A "cesta" [de produtos e serviços] [...] é integrada por atividades tradicionalmente desenvolvidas pelas equipes pedagógicas dos órgãos da administração pública e das escolas: formação continuada de educadores, efetivo acompanhamento das atividades docentes; investimento na produção e distribuição de materiais didáticos aos alunos; processos de avaliação externa e interna, entre as principais encontradas.
\end{abstract}

Portanto, os SAEs definem o material que será utilizado, fornecem formação continuada para os professores (muitas vezes com o intuito de treiná-los para o uso do material), auxiliam a gestão escolar no acompanhamento do trabalho dos docentes, são responsáveis por avaliações que os alunos farão (impondo, de certa maneira, o que deverá ser abordado em aula para que o aluno atinja os objetivos estipulados pelo próprio sistema), entre outras funções. Assim, o mercado passa a controlar aquilo que chega às salas de aulas, como os professores são formados e orientados e, também, influencia toda gestão escolar, devido às concepções de educação implícitas no sistema (Adrião et al., 2009).

Ao investigar os motivos que levaram à crença na qualidade dos sistemas para o ensino público, pesquisas, como as apresentadas em Adrião et al. (2009) e Nascimento (2012), indicam os seguintes aspectos: a homogeneização dos currículos no município por meio da adoção de um SAE padroniza as escolas, diminuindo as desigualdades e facilitando o intercâmbio de estudantes entre elas; a estrutura curricular pronta dos sistemas facilita o trabalho dos docentes menos preparados ou sobrecarregados; diferentemente dos livros didáticos, as apostilas são bens consumíveis, ou seja, pertencem aos estudantes e podem ser levadas para casa; sendo de origem privada, os materiais da rede pública passariam a ser semelhantes aos das escolas privadas, consideradas de qualidade; os sistemas fornecem cursos para capacitação dos professores; os sistemas assessoram a gestão escolar na busca por melhores resultados. Ainda que a realidade das escolas privadas seja diferente, os motivos que levam à adoção de um SAE são semelhantes. A organização curricular bem estruturada, o fornecimento de materiais e avaliações prontos, o auxílio da empresa à gestão da escola e a crença na qualidade dos materiais são os motivos mais destacados pelos professores e gestores de escolas privadas em pesquisas como as de Dantas; Almeida (2014) e Silva, E. F. (2016). 
Com base no exposto, pode-se perceber que a adoção de SAEs nas escolas tem uma grande implicação no trabalho docente. Sua estrutura altamente organizada e planejada retira do professor a tarefa de planejamento do ano letivo, seleção dos conteúdos a serem trabalhados, definição dos objetivos de aprendizagem e, muitas vezes, até a responsabilidade pela construção do instrumento de avaliação.

\section{A autonomia do profissional técnico}

A autonomia docente é uma ideia muito presente e frequentemente defendida no discurso pedagógico, especialmente nos últimos anos, visto as constantes mudanças no papel do professor na sociedade contemporânea. Por se tratar de um tema de grande importância, a expressão "autonomia docente" passou a se tornar mais um slogan discursivo, sendo utilizada de maneira leviana e sem um devido aprofundamento do seu significado. A sua utilização superficial tende a reforçar apenas um de seus sentidos, mais especificamente, aquele incentivado pelos detentores do poder na estrutura social para exercer maior controle sobre os discursos (Contreras, 2012). Nesse sentido, faz-se necessário contextualizar a autonomia docente dentro dos SAEs para compreender adequadamente seu potencial como conceito e o seu empobrecimento em um cenário de controle sobre a atividade do professor.

Para Contreras (2012), a discussão da autonomia do professor já começa em torno de sua própria condição de profissional. O assunto se torna problemático, pois a palavra "profissional" carrega consigo diversas opções e visões de mundo, de forma que o profissionalismo está longe de ser um tema neutro e com ausência de disputas no campo ideológico. Por um lado, o profissionalismo nasceria da busca pelo reconhecimento e prestígio social frente à desqualificação, visto que iria ao encontro das expectativas dos docentes de pertencerem a uma categoria exclusiva. Por outro lado, Contreras (2012) salienta que essa aspiração ao profissionalismo também possui armadilhas capazes de induzir os professores a erros, influenciando-os a colaborar com mudanças que os levarão a um processo de proletarização profissional. Nesse sentido:

a tese básica da proletarização de professores é que o trabalho docente sofreu uma subtração progressiva de uma série de qualidades que conduziram os professores à perda de controle e sentido sobre o próprio trabalho, ou seja, à perda de autonomia. (Contreras, 2012, p. 37).

Assim, a perda de autonomia ocorre não só pelo controle técnico imposto aos professores, mas também pela desorientação ideológica à qual os docentes são submetidos.

Partindo-se do pressuposto de que o conceito de autonomia é variável, Contreras (2012) desenvolve diferentes sentidos relacionados com três modelos de docentes: o especialista técnico, o profissional reflexivo e o intelectual crítico. No Quadro 1, estão apresentadas algumas características 
desses modelos, assim como o sentido de autonomia presente em cada um. Partindo do pressuposto que um professor que utiliza um SAE se aproxima do primeiro modelo, a análise deste artigo será centrada no modelo denominado por Contreras como especialista técnico.

\section{Quadro 1 - A autonomia profissional de acordo com os três modelos de professores}

\begin{tabular}{|c|c|c|c|c|}
\hline & \multicolumn{3}{|c|}{ Modelos de professores } \\
\hline & & $\begin{array}{c}\text { Especialista } \\
\text { técnico }\end{array}$ & $\begin{array}{c}\text { Profissional } \\
\text { reflexivo }\end{array}$ & $\begin{array}{c}\text { Intelectual } \\
\text { crítico }\end{array}$ \\
\hline \multirow{3}{*}{ 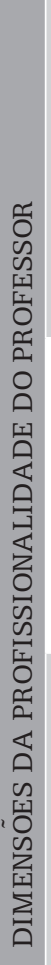 } & $\begin{array}{c}\text { Obrigação } \\
\text { moral }\end{array}$ & $\begin{array}{c}\text { Rejeição de } \\
\text { problemas } \\
\text { normativos. Os } \\
\text { fins e valores } \\
\text { passam a ser } \\
\text { resultados } \\
\text { estáveis e bem } \\
\text { definidos, os quais } \\
\text { se espera alcançar. }\end{array}$ & $\begin{array}{l}\text { O ensino deve } \\
\text { guiar-se pelos } \\
\text { valores educativos } \\
\text { pessoalmente } \\
\text { assumidos. }\end{array}$ & $\begin{array}{l}\text { Ensino dirigido } \\
\text { à emancipação } \\
\text { individual e } \\
\text { social, guiada } \\
\text { pelos valores de } \\
\text { racionalidade, } \\
\text { justiça e } \\
\text { satisfação. }\end{array}$ \\
\hline & $\begin{array}{c}\text { Compromisso } \\
\text { com a } \\
\text { comunidade }\end{array}$ & $\begin{array}{l}\text { Despolitização } \\
\text { da prática. } \\
\text { Aceitação das } \\
\text { metas do sistema } \\
\text { e preocupação } \\
\text { pela eficácia e } \\
\text { eficiência em seu } \\
\text { êxito. }\end{array}$ & $\begin{array}{c}\text { Negociação e } \\
\text { equilíbrio entre } \\
\text { os diferentes } \\
\text { interesses sociais, } \\
\text { interpretando seu } \\
\text { valor e mediando } \\
\text { política e prática } \\
\text { entre eles. }\end{array}$ & $\begin{array}{c}\text { Defesa de } \\
\text { valores para o } \\
\text { bem comum. } \\
\text { Participação em } \\
\text { movimentos } \\
\text { sociais pela } \\
\text { democratização. }\end{array}$ \\
\hline & $\begin{array}{l}\text { Competência } \\
\text { profissional }\end{array}$ & $\begin{array}{l}\text { Domínio técnico } \\
\text { dos métodos } \\
\text { para alcançar } \\
\text { os resultados } \\
\text { previstos. }\end{array}$ & $\begin{array}{l}\text { Pesquisa/reflexão } \\
\text { sobre a prática. } \\
\text { Deliberação na } \\
\text { incerteza acerca } \\
\text { da forma moral ou } \\
\text { educativamente } \\
\text { correta de agir em } \\
\text { cada caso. }\end{array}$ & $\begin{array}{l}\text { Autorreflexão } \\
\text { sobre as distorções } \\
\text { ideológicas e os } \\
\text { condicionantes } \\
\text { institucionais. } \\
\text { Participação na } \\
\text { ação política } \\
\text { transformadora. }\end{array}$ \\
\hline & $\begin{array}{l}\text { NCEPÇAO DA } \\
\text { AUTONOMIA } \\
\text { ROFISSIONAL }\end{array}$ & $\begin{array}{l}\text { Autonomia como } \\
\text { status. Autoridade } \\
\text { unilateral do } \\
\text { especialista. } \\
\text { Não ingerência. } \\
\text { Autonomia } \\
\text { ilusória: } \\
\text { dependência de } \\
\text { diretrizes técnicas, } \\
\text { insensibilidade } \\
\text { para os dilemas, } \\
\text { incapacidade } \\
\text { de resposta } \\
\text { criativa diante da } \\
\text { incerteza. }\end{array}$ & $\begin{array}{l}\text { Autonomia como } \\
\text { responsabilidade } \\
\text { moral individual. } \\
\text { Equilíbrio entre } \\
\text { a independência } \\
\text { de juízo e a } \\
\text { responsabilidade } \\
\text { social. Capacidade } \\
\text { para resolver } \\
\text { criativamente } \\
\text { as situações- } \\
\text { problema. }\end{array}$ & $\begin{array}{l}\text { Autonomia como } \\
\text { emancipação. } \\
\text { Consciência } \\
\text { crítica. Autonomia } \\
\text { como processo } \\
\text { coletivo dirigido } \\
\text { à transformação } \\
\text { das condições } \\
\text { institucionais e } \\
\text { sociais do ensino. }\end{array}$ \\
\hline
\end{tabular}

Fonte: Elaboração própria com base em Contreras (2012, p. 211). 
Conforme é possível observar no Quadro 1, Contreras (2012) identifica a construção de um modelo de racionalidade técnica para o professor quando o profissionalismo docente vem atrelado a uma ideologia cientificista e positivista. Sob essa perspectiva, o conhecimento científico é capaz de encontrar meios mais eficientes para a realização dos processos e das práticas profissionais, de forma que as soluções construídas pelos especialistas da área deveriam servir de referência para o trabalho do profissional. Assim, enxerga-se a atividade profissional como uma ação baseada em processos de causa e efeito que podem ser compreendidos de forma a ser possível prevê-los e manipulá-los. Sendo o trabalho previsível, não é necessário possuir um trabalhador capacitado para lidar com incertezas. O planejamento da prática pode ser desenvolvido por especialistas que definem, passo a passo, o que deve ser feito e os resultados esperados, tornando o professor apenas um especialista técnico responsável por aplicar aquilo que lhe foi designado. Conforme Contreras (2012, p. 113):

O docente técnico é o que assume a função da aplicação dos métodos e da conquista dos objetivos, e sua profissionalidade se identifica com a eficácia e eficiência nesta aplicação e conquista. Não faz parte de seu exercício profissional o questionamento das pretensões do ensino, mas tão somente seu cumprimento de forma eficaz.

Portanto, supõe-se uma dependência e subordinação dos professores para com os pesquisadores especialistas, gestores, elaboradores de currículo, autores de materiais didáticos, entre outros que decidem o que deve ou não fazer parte do currículo para que ele seja mais eficiente. Ainda, Contreras (2012, p. 117) defende que esse modelo revela uma "incapacidade para resolver e tratar tudo que é imprevisível, tudo o que não pode ser interpretado como um processo de decisão e atuação regulado segundo um sistema de raciocínio infalível", ignorando, assim, todos os elementos do fazer docente que envolvem a incerteza, o imprevisto e as situações de conflito.

Para Contreras (2012), os mecanismos de controle associados a esse modelo continuam permitindo que o professor mantenha saberes profissionais específicos (técnicas didáticas e conhecimento da área a ser ensinada), mantendo um status diferenciado para a categoria profissional, que continua se vendo como categoria autônoma. Além disso, esses mecanismos vêm se sofisticando e se tornando mais sutis, dificultando ainda mais a percepção do controle ao que se está submetido. Para o autor, diversas estratégias são utilizadas para amenizar as restrições e conseguir que o corpo docente queira colaborar com a estrutura que está sendo imposta. Sob o disfarce de elementos positivos, como abertura ao diálogo, trabalho em equipe, melhora de resultados, flexibilização do trabalho, entre outros, Contreras (2012) argumenta que essas estratégias são armadilhas que cedem pequenos espaços de autonomia apenas para legitimar (e camuflar) o controle exercido. De acordo com ele, parece haver espaço para intervenção e mudança, mas, na verdade, essa abertura se dá apenas em aspectos superficiais, enquanto toda a estrutura e ideologia do processo educacional continuam reproduzindo aquilo que os elaboradores 
do currículo esperam. Levando em consideração o exposto, o professor incluído no modelo de especialista técnico exerceria uma função "despolitizada", pouco questionando os objetivos que lhe são impostos, pois obtê-los qualificaria seu trabalho como eficiente e eficaz. A crença na autonomia, então, estaria associada a uma ilusão do profissional frente ao seu status profissional e a relativa liberdade para conduzir as atividades em sala de aula, mesmo que seja uma prática limitada por parâmetros externos. Assim, o professor especialista técnico teria uma "autonomia ilusória", não se constituindo como um educador verdadeiramente autônomo e capaz de construir uma prática pedagógica transformadora com seus colegas, seus alunos e sua comunidade.

\section{A visão dos docentes na literatura}

Com o crescimento dos grandes grupos educacionais e da venda de sistemas de ensino, o número de pesquisas sobre SAEs vem crescendo nos últimos anos. Algumas delas, como as que serão apresentadas nessa seção, buscaram compreender a visão dos professores sobre os sistemas e como eles sentem que seu trabalho foi afetado. É interessante ressaltar que muitos dos pesquisadores partem da hipótese de que os professores serão críticos aos sistemas e ao controle que sofrem em seu trabalho devido à estrutura curricular imposta. Contudo, percebe-se que a maioria deles costuma se posicionar favoravelmente ao uso dos SAEs. Quais seriam, então, os motivos levados em consideração pelos professores para defender o uso desses sistemas?

Silva, E. A. (2013), aplicando um questionário a 36 professores dos anos iniciais do ensino fundamental da rede pública, percebeu que a maioria dos participantes afirma que o SAE é uma boa solução para melhorar a qualidade do ensino no município. Para eles, isso ocorre porque os materiais são melhores que os livros didáticos e facilitam tanto a aprendizagem do estudante quanto o trabalho do professor. Assim, foi constatado que esses materiais têm sido utilizados para toda a organização didática desses professores, desde o planejamento até o desenvolvimento das aulas. Reforçando esses resultados, Silveira (2015) entrevistou professores após a suspensão do uso de um SAE em uma escola e se surpreendeu ao constatar que os docentes não ficaram insatisfeitos com a adoção do SAE sem consultá-los, mas, sim, com a sua suspensão. Salvo um professor de Matemática, nenhum dos outros sentia que o material apostilado limitava ou enrijecia o trabalho pedagógico, pois, para a maioria, ele facilitava o trabalho na sala de aula. De forma semelhante, mas na rede privada, Silva, E. F. (2016) e Dantas; Almeida (2014) identificaram que a maioria dos professores das escolas se diz satisfeita com o uso do SAE, pois eles gostam da existência de um material que os oriente e acreditam que o sistema soluciona problemas pedagógicos, administrativos e de controle financeiro.

No contexto específico da educação infantil, Damaso (2015) questionou os professores sobre as vantagens e desvantagens do uso do SAE. 
Curiosamente, as principais críticas dos professores às apostilas foram com relação à falta de determinados conteúdos, de atividades de alfabetização e de lições para casa. Portanto, não se questionou a organização do trabalho pedagógico pelo sistema, pelo contrário, esperava-se que o sistema fornecesse mais elementos com os quais o professor pudesse trabalhar. Ademais, as vantagens apresentadas também fizeram menção aos materiais, que foram elogiados por terem uma melhor sequência na aprendizagem, trazerem uma diversidade de temas, serem multidisciplinares, trabalharem com atividades concretas, com a coordenação motora e com o lúdico, entre outros pontos. Embora, na educação infantil, os professores entrevistados por Souza (2017) possuíssem uma percepção diferente dos materiais disponibilizados pela empresa, por acharem que os autores não tinham clareza das diversas realidades de crianças de diferentes contextos socioeconômicos, ainda assim, num aspecto mais geral, suas opiniões sobre o SAE reforçam os dados das outras pesquisas, visto que 28 dos 52 entrevistados afirmaram preferir a permanência do sistema na escola.

Uma pesquisa interessante é a de Carvalho (2011), pois não investiga o uso de um SAE de empresa privada, mas, sim, um sistema apostilado produzido pelo estado de São Paulo, visando à padronização do currículo na rede (Programa São Paulo Faz Escola). A autora percebeu que muitos professores se sentiram incomodados com a imposição do sistema, mas que alguns se adaptaram melhor que outros. Os professores menos experientes e sem uma formação inicial de qualidade demonstraram uma tendência a ficar ansiosos e inseguros, assumindo o papel de técnicos que aplicam as apostilas, passam respostas no quadro e evitam dar explicações. Por outro lado, os professores mais experientes foram os que mais conseguiram se beneficiar com o sistema, na medida do possível, apesar de também não terem aprovado plenamente o novo formato. Resultados semelhantes são apresentados por Adrião, Damaso e Galzerano (2013), que perceberam que os professores menos experientes tinham uma tendência maior a acreditar que os materiais eram relevantes. Ainda assim, muitos professores experientes também apoiaram o uso do material, visto que $69 \%$ dos entrevistados afirmaram que continuariam usando o material se pudessem escolher, contra $24 \%$ que optariam por não usar.

Em alguns casos, como constatado por Bego (2013), os professores até relatam problemas para se adaptarem aos materiais. Contudo, assim como nas outras pesquisas, os docentes afirmam que o sistema acabou sendo aceito e teve boa receptividade pela comunidade escolar. Acreditando que os materiais das empresas privadas possuíam uma melhor qualidade, os professores defendiam que eles facilitavam as atividades cotidianas e apresentavam resultados positivos para a aprendizagem.

Já em pesquisas como a de Amorim (2012), a maioria dos professores entrevistados identifica falhas nos materiais e alega que eles são apenas um suporte para planejar as aulas. Ainda que o discurso seja esse, $40 \%$ dos professores afirmaram adotar as apostilas durante os cinco dias letivos da semana e 31,1\%, durante quatro. Além disso, mais da metade dos professores declarou considerar o uso das apostilas como positivo. 
Não obstante demonstrarem ser favoráveis ao uso, 51,1\% declararam que as apostilas não alteraram o rendimento dos estudantes, $20 \%$ entenderam que o rendimento deles piorou e apenas $22,2 \%$ acreditaram que melhorou (6,7\% não responderam). Pensando nisso, os professores parecem defender seu uso mais por sentirem um aumento na facilidade de execução do seu trabalho de planejamento do que por uma melhora na aprendizagem dos estudantes de fato.

Por fim, ao realizar sua pesquisa, Janke (2018) alega ter percebido que o SAE permitia uma relativa autonomia aos professores para que desenvolvessem outras atividades além daquelas presentes nas apostilas. Todavia, verificou-se que as avaliações dos estudantes são feitas pela própria empresa, o que significa que ela decide o que será necessário aprender para que os estudantes obtenham bons resultados. Dessa forma, por medo de retaliações por parte da gestão escolar, os professores podem se sentir induzidos a trabalhar mais com o conteúdo dos materiais para que seus alunos não tenham um desempenho inferior aos demais. Além disso, mesmo que o professor tenha liberdade de não utilizar as apostilas, a autora questiona qual seria a razão de investir tanto dinheiro público em materiais que podem não ser utilizados. Logo, se a rede pública investe alto nos materiais, espera-se que eles sejam usados em sala de aula. Portanto, ela também defende a existência de uma autonomia relativa para o trabalho docente dentro do SAE.

Isso posto, Dantas; Almeida (2014) defendem que o marketing das empresas tem funcionado, convencendo grande parte da comunidade escolar de que o material fornecido é de alta qualidade por ser produzido por especialistas. Já Damaso (2015) e Silva, E. F. (2016) acreditam que essa aprovação dos SAEs pelo corpo docente também indica uma falta de reflexão crítica desses profissionais, o que seria resultado de uma formação acadêmica pouco consistente.

Quanto às consequências desse cenário, Damaso (2015) e Silva, E. F. (2016) preconizam que os materiais desqualificam o trabalho docente, visto que o professor deixa de ser o responsável pelo planejamento e a consequente reflexão do ato educativo, tendo que se moldar aos objetivos educacionais impostos pelos sistemas, mesmo que de maneira mais sutil. Além disso, como constata Silveira (2015), mesmo quando se envolvem em algum planejamento, os professores que utilizam sistemas tendem a se apoiar muito nas apostilas, as quais são fragmentadas e disciplinares, desestimulando o planejamento coletivo e interdisciplinar entre eles. Com o sistema atuando como guia do trabalho escolar, Bego (2013) acredita que os planos de aula e o projeto político-pedagógico são cada vez mais encarados como documentos burocráticos elaborados apenas para seguir as normas.

\section{Sistemas apostilados e ilusão de autonomia}

Refletindo sobre as características das apostilas e dos SAEs de forma geral, defende-se aqui uma proximidade do trabalho docente nesse cenário com as características do profissional técnico apresentado por 
Contreras (2012). Por mais que as empresas aleguem que o professor tem liberdade para realizar seu trabalho em sala de aula, percebem-se algumas características nessas parcerias que induzem o professor, de forma mais ou menos sutil, a um trabalho controlado pelo sistema.

Primeiramente, como destacado por Janke (2018) e outros autores, qual seria o sentido de realizar um grande investimento em materiais para que não fossem utilizados pelos professores? Dessa forma, desde o momento no qual a parceria é firmada (tanto na rede pública quanto na privada), já existe uma certa pressão para que os professores não desperdicem o investimento realizado e utilizem o material do SAE. Nas escolas privadas, essa pressão é maior ainda, visto que o investimento vem diretamente da escola e/ou das famílias dos estudantes. Isso posto, a não utilização dos materiais pode levar a uma série de questionamentos por parte destes e, consequentemente, acarretar instabilidade do professor no emprego. Por se sentirem responsáveis pelo processo educacional e pela boa atuação profissional, os professores acabam coagidos a agir "profissionalmente" e colaborar com o trabalho da escola. Como afirma Contreras (2012, p. 74) sobre as armadilhas do profissionalismo: "A participação se constrói como um requisito do profissionalismo responsável, de modo que, não colaborar seria uma falta de profissionalismo". Assim, induzidos a colaborar por uma suposta melhora na educação escolar, os professores assumem a responsabilidade de realizar uma boa prática com a estrutura organizada pela escola sem questionar a parcialidade de sua autonomia.

Como resposta aos questionamentos nessa linha, as empresas salientam que o professor não precisa se limitar às apostilas e às "sugestões" de aulas propostas, podendo realizar outras atividades e explorar outros aspectos da disciplina que não estejam previstos nos materiais. Ainda assim, notam-se dois problemas nesse sentido. O primeiro diz respeito ao fato de que costumam ser fornecidas apostilas para cada bimestre ou trimestre com uma quantidade muito grande de conteúdos e exercícios para serem trabalhados. Dessa maneira, o professor deve fazer o possível para "vencer o conteúdo" das apostilas dentro do período curricular estipulado, não restando muito tempo para trabalhar outros temas que poderiam ser do seu interesse ou do interesse dos estudantes (Dantas; Almeida, 2014).

O segundo aspecto sobre a falácia da flexibilidade é com relação às avaliações realizadas com os estudantes. Quando a avaliação é planejada e realizada pelo professor, ele tem maior controle sobre os objetivos esperados e, consequentemente, irá basear a avaliação em seu trabalho de sala de aula. Contudo, percebem-se duas estratégias dos SAEs que podem interferir na liberdade do professor de avaliar seus alunos. A primeira, mais indireta, está na elaboração e aplicação, por parte do sistema, de provas que tentam simular os vestibulares e o Enem. Mesmo que não sejam utilizadas para avaliar os estudantes em termos de notas ou aprovação nas disciplinas, os resultados costumam ser avaliados pelas escolas. A segunda estratégia, menos comum, é quando parte da avaliação dos estudantes está vinculada diretamente a uma nota obtida em provas produzidas pelo próprio sistema. Às vezes, nem é o professor que aplica essa prova aos seus estudantes. 
Pensando nisso, o professor que optar por negligenciar os materiais da empresa e suas sugestões pode acabar não preparando os estudantes para o tipo de avaliação que é planejada pelo sistema. Independentemente da qualidade do ensino proporcionado pelo professor, a obtenção de resultados negativos por parte de seus estudantes também será um fator de desconforto para a gestão escolar, o que gera mais instabilidade para a manutenção do seu emprego.

Dessa forma, o discurso da flexibilidade do sistema parece mais uma tentativa de criar um mecanismo de controle mais sutil e eficaz, para conseguir a colaboração do professor, do que uma concessão legítima de autonomia para o exercício profissional. De acordo com Contreras (2012, p. 74):

Passa-se da imposição à participação, de um "currículo fechado" como mandato a um "currículo aberto" como guia interpretável, da obediência à autonomia profissional e do treinamento ao desenvolvimento profissional. Mas tudo isso ocorre sob esquemas e estruturas de racionalização que não podem ser abandonados, com sistemas de controle de resultados perfeitamente delimitados e definidos, com formas de dar alento ao trabalho de colaboração nos centros que "incorporam o professor e sua lealdade a propósitos e estruturas burocraticamente determinados em outro lugar" [...].

Além desses fatores, a empresa também pode se valer de métodos ainda mais sutis para influenciar o trabalho em sala de aula, como a oferta de cursos de formação continuada que alegam capacitar o corpo docente. Contudo, como observado por Prado (2013), esses cursos costumam ter um caráter transmissivo e fragmentado, muitas vezes focados no treinamento para uso dos materiais apostilados. Portanto, os cursos oferecidos pelas empresas não visam à construção autônoma, crítica e coletiva de conhecimentos pelos professores da escola, mas, sim, transmitir aquelas informações que acreditam que os professores necessitam. O sistema se coloca na posição de detentor do conhecimento, apresentando intelectuais especialistas mais capacitados para mostrar aos professores como eles devem realizar o seu trabalho na aplicação de métodos de ensino e uso do material, assim como profissionais técnicos.

Ainda assim, as pesquisas apresentadas demonstram que um número significativo de professores se mostra favorável ao uso dos SAEs em suas escolas. Pensando nisso, por qual motivo os professores conscientemente apoiariam um sistema que lhes tira autonomia e controla o seu trabalho? Para Contreras (2012), isso ocorre justamente na medida em que esses profissionais não se percebem sem autonomia. Como indicado por determinados trabalhos, alguns docentes dizem possuir autonomia devido à possibilidade de que, dentro de sua sala de aula, podem utilizar também outros materiais escolhidos por eles, propor atividades diferentes e decidir quais os conteúdos que receberão mais atenção e quais atividades podem ser deixadas de lado. Ainda assim, pensando nos argumentos apresentados anteriormente, nota-se que essa suposta autonomia está fortemente controlada, regulada e influenciada pelos objetivos educacionais impostos 
pelos sistemas, situação que Amorim (2015) irá chamar de docência administrada. Dessa maneira, os professores estariam vivenciando o que Contreras (2012) denomina de autonomia ilusória para o profissional técnico.

Ademais, é interessante refletir sobre o argumento dos professores em defesa dos sistemas ao afirmarem que esses facilitam o trabalho docente. O primeiro aspecto a se destacar é que essa facilitação ocorre justamente na medida em que retira do professor a responsabilidade de todo o trabalho intelectual de planejamento e reflexão sobre os fins e objetivos educacionais. Assim, os professores acabam por apoiar o que Contreras (2012) chama de processo de proletarização profissional.

Com uma visão semelhante, Giroux (1997, p. 158) afirma que a proletarização dos professores os reduz ao papel de "técnicos especializados dentro da burocracia escolar, cuja função, então, torna-se administrar e implementar programas curriculares, mais do que desenvolver ou apropriar-se criticamente de currículos que satisfaçam objetivos pedagógicos específicos". Assim, a perda de autonomia ocorre não só pelo controle técnico imposto aos professores, mas também pela desorientação ideológica à qual os docentes são submetidos. Visão semelhante é compartilhada pelas pesquisas de Bego (2013), Amorim (2015), Damaso (2015), entre outros, ao afirmarem que a retirada de autonomia do professor para exercer essas funções contribui para aumentar a precarização da profissão e sua consequente desvalorização.

Percebe-se uma grande semelhança entre a defesa dos SAEs feita pelos professores por eles controlados e o discurso sobre a servidão voluntária, de Etienne de La Boétie. Já no século 16, La Boétie se perguntava quais seriam as razões para o povo se submeter voluntariamente a algo que lhe tolhia a liberdade. Para La Boétie (2009, p. 36), "é o povo que se escraviza e se suicida quando, podendo escolher entre ser submisso ou ser livre, renuncia à liberdade e aceita o jugo; quando consente com seu sofrimento, ou melhor, o procura".

Embora, à primeira vista, a utilização do conceito desenvolvido por La Boétie possa parecer descabida ao caso da atuação dos professores no âmbito dos SAEs, a ideia de servidão voluntária, segundo o autor, está arraigada no nascimento de um modelo de Estado que é fundado na divisão de classes, entre os que mandam e os que servem (Wendling, 2018). Não à toa, Clastres (1999) entende que o conceito de servidão voluntária é "trans-histórico".

O conceito se mantém atual, pois o capitalismo apropriou-se dessa relação de servidão e a instrumentalizou; mais do que isso, a ideia de servidão voluntária está na base da lógica de funcionamento do sistema capitalista, tendo sido fundamental para sua expansão e consolidação (Fontes, 2006). Nesse sentido, apesar de ter ocorrido uma modificação nos meios de controle ao longo do tempo, de maneira coerente com a própria estruturação e organização do capitalismo, o elemento da voluntariedade da servidão não está ligado à existência de controle (seja físico ou ideológico), pois, para La Boétie (2009), a servidão é voluntária pelo medo da liberdade, e não pelo medo do tirano. 
Como os próprios professores afirmam em sua defesa, o sistema facilita o seu trabalho, ou seja, a falta de liberdade é mais fácil, tira-lhes a responsabilidade da reflexão e torna a sua função mais confortável. Inconscientemente, enganam-se a si próprios e aceitam o exercício de uma função mais simples, acrítica e tecnicista devido ao conforto intelectual que essa posição lhe proporciona. Assim, são os próprios docentes, submissos ao sistema, que dão força, sustentam e permitem que a empresa cresça e se fortaleça.

Nessa linha, a reflexão de La Boétie mostra-se pertinente e atual para despertar a reflexão daqueles que defendem a autonomia do trabalho dentro de um SAE:

Sede resolutos em não querer servir mais e sereis livres. Não vos peço que o enfrenteis ou o abaleis, mas somente que não o sustenteis mais, e o vereis, como grande colosso do qual se retirou a base, despencar e despedaçar-se debaixo do próprio peso. (La Boétie, 2009, p. 39).

\section{Considerações finais}

Neste artigo, foram apresentados argumentos para problematizar a autonomia docente dentro dos Sistemas Apostilados de Ensino. Percebendo que muitos professores defendem o uso dos sistemas, buscou-se em Contreras (2012) o conceito de autonomia ilusória do profissional técnico para tentar compreender esse posicionamento dos docentes.

Com base nos dados de pesquisas sobre os SAEs, debateu-se que as empresas se valem de uma série de mecanismos mais ou menos sutis para controlar o trabalho docente. Nesse cenário, retira-se do professor o papel de planejamento, de reflexão crítica e de decisão de o que abordar durante o ano letivo, além de induzi-lo a trabalhar com as sugestões dos materiais para evitar problemas com a gestão escolar. Além disso, por meio dos cursos de formação continuada e de um efetivo marketing das empresas, elas conseguem, aos poucos, legitimar sua imagem de sistema educacional de qualidade, influenciando os professores a acreditarem que seu uso vai necessariamente acarretar em uma melhora nos processos de ensino e de aprendizagem. Dessa forma, afastados de determinadas funções intelectuais do processo educacional, os professores se assemelhariam ao modelo de profissional técnico que se limita a aplicar métodos de ensino para os objetivos educacionais determinados externamente. Assim, sua liberdade para trabalhar dentro da sala de aula está sempre restrita a um contexto organizacional que já lhe foi imposto, caracterizando sua autonomia como ilusória, conforme proposto por Contreras (2012).

Defende-se que um dos principais argumentos dos professores em defesa dos SAEs, a facilitação do trabalho docente, só ocorre na medida em que desqualifica o trabalho do professor, retirando-lhe o status de profissional reflexivo, intelectual e crítico. Portanto, o discurso desses 
docentes vai ao encontro do discurso sobre a servidão voluntária, de La Boétie, na medida em que esses profissionais defendem a manutenção da sua falta de liberdade em nome do conforto que ela lhes proporciona. Assim, enquanto aqueles mais controlados pelo sistema não optarem por deixar de apoiá-lo, eles se manterão com força e continuarão a crescer exponencialmente, como vem ocorrendo. Em uma época de crescimento da doutrina capitalista neoliberal e de formas mais sutis de controle ideológico, espera-se que essa pesquisa auxilie no debate sobre o papel do professor numa educação mais crítica, reflexiva e autônoma.

\section{Referências}

ADRIÃO, T. M. et al. Uma modalidade peculiar de privatização da educação pública: a aquisição de "sistemas de ensino" por municípios paulistas. Educação \& Sociedade, Campinas, v. 30, n. 108, p. 799-818, out. 2009.

ADRIÃO, T. M. et al. Grupos empresariais na educação básica pública brasileira: limites à efetivação do direito à educação. Educação \& Sociedade, Campinas, v. 37, n. 134, p. 113-131, jan./mar. 2016.

ADRIÃO, T. M.; DAMASO, A.; GALZERANO, L. S. A adoção de sistemas privados de ensino em escolas públicas de educação infantil: reflexões a partir do perfil dos professores. Revista e-Curriculum, São Paulo, v. 11, n. 2, p. 434-460, ago. 2013.

AMORIM, I. F. Reflexões críticas sobre os Sistemas Apostilados de Ensino. 2008. 191 f. Dissertação (Mestrado em Educação Escolar) Faculdade de Ciências e Letras, Universidade Estadual Paulista, Araraquara, 2008.

AMORIM, I. F. Indústria cultural e Sistemas Apostilados de Ensino: a docência administrada. 2012. 199 f. Tese (Doutorado em Educação Escolar) - Faculdade de Ciências e Letras, Universidade Estadual Paulista, Araraquara, 2012.

AMORIM, I. F. Docência administrada: uma análise crítica da autonomia do professor. Comunicações, Piracicaba, v. 22, n. 3, p. 35-48, 2015.

BEGO, A. M. Sistemas Apostilados de Ensino e trabalho docente: estudo de caso com professores de Ciências e gestores de uma rede escolar pública municipal. 2013. $334 \mathrm{f}$. Tese (Doutorado em Educação para a Ciência) - Faculdade de Ciências, Universidade Estadual Paulista, Bauru, 2013. 
CARVAlHO, M. C. A prática docente do professor de Matemática e o Sistema Apostilado de Ensino do estado de São Paulo. 2011. 146 f. Dissertação (Mestrado em Educação) - Universidade Católica de Santos, Santos, 2011.

CLASTRES, P. Liberdade, mau encontro, inominável. In: LA BOÉTIE, E. Discurso da servidão voluntária. São Paulo: Brasiliense, 1999. p. 109-123.

CONTRERAS, J. A autonomia de professores. São Paulo: Cortez, 2012.

DAMASO, A. F. F. O uso do material apostilado em creches municipais paulistas: a percepção dos professores. 101 f. 2015. Dissertação (Mestrado em Educação) - Faculdade de Educação, Universidade Estadual de Campinas, Campinas, 2015.

DANTAS, F. B. A.; ALMEIDA, C. M. C. Os "pacotes didáticos" na educação infantil e no ensino fundamental. Educação em Foco, Belo Horizonte, v. 17, n. 24, p. 229-253, dez. 2014.

FONTES, V. Da atualidade da servidão voluntária. Trabalho, Educação e Saúde, Rio de Janeiro, v. 4, n. 2, p. 431-440, set. 2006.

GALZERANO, L. S.; GOBI, R. C.; LUIZ, K. T. Breve retrato da atuação dos grupos empresariais Objetivo, COC e Positivo nos municípios do estado de São Paulo. Educação: Teoria e Prática, Rio Claro, SP, v. 21, n. 38, p. 98-113, out./dez. 2011.

GIROUX, H. A. Os professores como intelectuais: rumo a uma pedagogia crítica da aprendizagem. Porto Alegre: Artes Médicas, 1997.

JANKE, R. R. Relações público-privado na rede pública de um município da região Celeiro: gerencialismo e padronização pedagógica. 2018. 109 f. Dissertação (Mestrado em Educação) - Universidade Regional Integrada do Alto Uruguai das Missões, Frederico Westphalen, 2018.

LA BOÉTIE, É. Discurso sobre a servidão voluntária. 2. ed. São Paulo: Martin Claret, 2009.

LAVAL, C. A escola não é uma empresa: o neo-liberalismo em ataque ao ensino público. Tradução de Maria Luiza M. de Carvalho e Silva. Londrina: Planta, 2004.

NASCIMENTO, M. L. B. P. As políticas públicas de educação infantil e a utilização de Sistemas Apostilados no cotidiano de creches e pré-escolas públicas. Revista Brasileira de Educação, Rio de Janeiro, v. 17, n. 49, p. 59-80, jan./abr. 2012.

PIERONI, R. F. A expansão do ensino franqueado: um estudo de caso. 1998. 231 f. Dissertação (Mestrado em Educação) - Faculdade de Educação, Universidade Estadual de Campinas, Campinas, 1998. 
PRADO, G. J. Formação continuada de professores e a municipalização do ensino: o processo de parceria entre municípios e sistemas privados de ensino no Polo 20 da UNCME - SP. 2013. 142 f. Dissertação (Mestrado em Educação) - Faculdade de Educação, Universidade de São Paulo, São Paulo, 2013.

SILVA, E. A. Sistemas Apostilados de Ensino: as percepções dos professores dos anos iniciais do ensino fundamental de Alvares Machado - SP. 2013. 239 f. Dissertação (Mestrado em Educação) Faculdade de Ciências e Tecnologia, Universidade Estadual Paulista, Presidente Prudente, 2013.

SILVA, E. F. Reflexões sobre o uso do Sistema Apostilado de Ensino: o que dizem os professores de uma escola da rede particular. 2016. 80 f. Dissertação (Mestrado em Linguística Aplicada) - Universidade de Taubaté, Taubaté, 2016.

SILVEIRA, R. J. "Sistema privado de ensino" na educação pública municipal: trabalho docente e organização do ensino nos anos finais do ensino fundamental. 2015. 171 f. Dissertação (Mestrado em Educação) - Faculdade de Filosofia, Ciências e Letras, Universidade de São Paulo, Ribeirão Preto, 2015.

SOUZA, T. N. Diretrizes curriculares nacionais para a educação infantil em contexto de uso de sistemas privados de ensino: a análise de concepções de professoras de pré-escolas. 2017. 219 f. Tese (Doutorado em Educação Escolar) - Faculdade de Ciências e Letras, Universidade Estadual Paulista, Araraquara, 2017.

WENDLING, M. Psicanálise e política: sobre a servidão voluntária. Clínica \& Cultura, São Cristóvão, v. 7, n. 2, p. 46-60, jul./dez. 2018.

Recebido em 6 de abril de 2021.

Aprovado em 12 de julho de 2021. 